\title{
ABRIR, CERRAR, SUBIR Y BAJAR: LA PRODUCTIVIDAD DE LOS VERBOS DE MOVIMIENTO COMO ELEMENTOS CONSTITUTIVOS DE LOCUCIONES IDIOMÁTICAS EN ESPAÑOL ${ }^{1}$
}

\section{INTRODUCCIÓN: LAS LOCUCIONES IDIOMÁTICAS Y LOS USOS FIGURADOS}

Abrir la mano, cerrar el grifo, bajarse los pantalones o subirse a la parra son expresiones que, obviamente como la mayoría de las combinaciones sintagmáticas, son susceptibles de ser interpretadas literalmente en español; así, los hablantes entendemos que alguien puede abrir la mano que previamente había cerrado, puede cerrar un grifo para que deje de salir el agua, puede bajarse los pantalones cuando lo considere oportuno o puede, aunque no sea tan frecuente, subirse a una parra. ${ }^{2}$ En todos estos casos el sujeto realiza una acción que viene indicada por un verbo que implica movimiento y que es el que encabeza las citadas construcciones: abrir, cerrar, bajar o subir.

Ahora bien, estas expresiones pueden funcionar también, y es lo más habitual, como locuciones idiomáticas, es decir, como expresiones figuradas en las que su significado no es deducible a partir de la suma de los significados de los elementos que las componen. ${ }^{3}$ En este sentido, el verbo de movimiento presente en estas estructuras

\footnotetext{
* Dirección de la autora: Facultad de Filosofía y Letras, Ciudad Universitaria de Cantoblanco, C/ Tomás y Valiente 1, 28049 Madrid, España. Correo electrónico: ana.serradilla@uam.es

${ }^{1}$ Este trabajo ha sido llevado a cabo en el marco del Proyecto de Investigación «Diccionario electrónico multilingüe de verbos amplios de movimiento (andar, ir, venir y volver)» (FFI200912191), dirigido por Elena de Miguel. También ha sido parcialmente financiado por el Proyecto dirigido por Inés Fernández Ordóñez: «Variación y cambio en la sintaxis del español peninsular» (FFI2009-10817). Ambos proyectos están financiados por el Ministerio de Ciencia e Innovación de España.

2 Agradezco a Jacinto González Cobas y a Santiago U. Sánchez Jiménez la lectura de la primera versión de este trabajo y sus siempre minuciosas e inteligentes observaciones, que han servido para enriquecer este estudio.

${ }^{3}$ Son muchos los trabajos que analizan las características que ha de tener una expresión para ser considerada locución idiomática o frase hecha; véanse los estudios de Corpas (1997, 2003a, 2003b), García-Page (2008), Gómez Molina (2004), Koike (2001), Lewis (1993), Wotjak (1998) o el clásico de Zuluaga (1992), entre otros. Especialmente, quiero llamar la atención sobre el reciente trabajo de García-Page, pues recoge las propuestas hechas desde diferentes posiciones teóricas y presenta la bibliografía más completa y actualizada que en estos momentos puede encontrarse en torno a la fraseología. Dado que en artículos anteriores me he centrado en este punto (Serradilla 2001, 2004, 2006), me remito a ellos y a los estudios anteriormente citados para una mayor profundización en el tema.
} 
deja de implicar un movimiento real para pasar a significar un movimiento figurado, a partir de una extensión metafórica.

En este trabajo me fijaré únicamente en los valores metafóricos de estas construcciones y analizaré la capacidad de cada uno de los verbos que constituyen estas expresiones para utilizarse de forma figurada. Es de destacar que los verbos seleccionados participan en estructuras de este tipo desde antiguo y todavía hoy siguen siendo productivos en la creación de frases hechas debido a la existencia de metáforas universales («arriba» es positivo mientras que «abajo» es negativo). Me detendré en el análisis del significado de cada uno de estos verbos y de sus posibilidades estructurales, me centraré en su rentabilidad para participar en expresiones figuradas, y, finalmente, compararé la situación del español con la de otras lenguas.

\section{LOCUCIONES CON ABRIR, CERRAR, SUBIR Y BAJAR EN LA HISTORIA DEL ESPAÑOL: EL TESORO DE COVARRUBIAS}

Como he avanzado, los verbos de movimiento aparecen en locuciones idiomáticas desde épocas remotas. Forment (2000: 379) señala:

[...] Las metáforas que motivaron los sentidos idiomáticos de algunas expresiones vienen actuando desde la Antigüedad y han regido parte de la conceptualización del mundo desde la civilización romana. De este modo, es obvio afirmar que la acuñación de algunas locuciones del español se produjo en estadios anteriores de la lengua, y que lo único que han hecho los hablantes ha sido ir repitiéndolas hasta conseguir su institucionalización.

Se trata de una afirmación de especial relevancia para su constatación en las lenguas románicas (que demostraría su conservación genética); y aun más relevante en su comparación con lenguas no románicas, por su valor universal; valor sobre el que después volveré.

En este primer apartado me detendré, aunque sea de manera muy breve, en el análisis de algunas de estas expresiones que están documentadas en español desde antiguo. Tomaré como corpus básico la obra de Covarrubias (1611) -obra pionera en la lexicografía española en la que se recogen multitud de expresiones utilizadas en la época, pero también otras que contaban con gran tradición aunque estuvieran ya en desuso-.

En un trabajo anterior (Serradilla 2006) ya me adentré en el Tesoro de Covarrubias con el fin de observar la presencia de determinadas locuciones con verbos de movimiento en el español clásico; en este artículo limitaré mi campo de estudio a las fórmulas construidas por abrir, cerrar, subir y bajar. ${ }^{4}$ A continuación, detallo las expresiones que, con estos verbos, se recogen en el citado diccionario:

ABRIR: abrir puerta, abrir tienda, abrir el ojo, abrir la cabeza, abrir camino, abrir la mano, abrir el cuello, abrirse en las razones.

\footnotetext{
${ }^{4}$ Los dos primeros verbos no fueron tenidos en cuenta para el trabajo mencionado y los dos últimos verbos citados no se analizaron en profundidad pues el número de locuciones localizado no fue considerado como muy relevante, al menos en comparación con otros como caer, ir, llevar, echar, etc.
} 
CERRAR: cerrarse de campiña, cerrar los ojos, cerrarse la mollera, cerrar la cuenta, cerrarse las velambres, cerrarse las heridas, cerrar puerta.

BAJAR: bajar la cabeza, bajar el tono, bajar el halcón de carnes, bajar de punto y bajar las calzas.

SUBIR: subir al cielo sin escalera, subir el humo a la chimenea, subirse el humo a las narices, subirsele la mostaza a las narices, subirse en el canto y subirse de punto.

A estas expresiones podemos sumarle otras recogidas por Cejador ${ }^{5}$ como subirse a mayores ('por mandar, siendo menor') o callar el pico / su pico ('no hablar, darse por desentendido'), similar a la actual cerrar el pico.

A continuación se recogen algunos ejemplos que ilustran el uso de estas locuciones en el español clásico: ${ }^{6}$

1. Lo que más hemos menester todos, es que no le dejen comer con esa gente, y que ande Su Paternidad avisado en ello, pues nos hace Dios tanta merced de darle salud con tantos trabajos. Lo de el lino y lana junto, más quiero que trayan lienzo, cuando lo hayan menester, que es abrir puerta para nunca cumplir bien la Costitución, y con traer lienzo con necesidad la cumplen. Esotro dará casi tanta calor, y ni se hace lo uno ni lo otro, y quedarse han con ello. (1576, Santa Teresa de Jesús, Carta a la M. María de San José, priora de Sevilla. Toledo, 19 de noviembre de 1576 [Epistolario])

2. *LAÍS. Ramera famosíssima. Aviendo naçido en Sicilia vino a abrir tienda a Corintho y por esto la llamaron Corinthia. Por su gran hermosura fue reqüestada de los grandes príncipes y señores de Graecia y a ninguno admitía que no fuese con grande interés, de donde nació el proverbio, non cuiusvis hominis est adire Corinthum [no todo el mundo puede visitar Corinto]. Espantado Demóstenes del gran preçio que pedía por sóla una noche respondió ego tanti paenitere non emo [yo no pago tanto para arrepentirme]. Fue Lays a Thessalia y los galanes la servían con tanto afecto que las mugeres de aquella tierra tiniendo çelos de ella la mataron en unos sacrificios en los quales no podían intervenir hombres, y por esta crueldad sobrevino en Thesalia una gran peste. (1611, Covarrubias: Suplemento al Tesoro de la lengua española castellana)

3. Sé también por espías verdaderas que han entrado en ese lugar cuatro personas disfrazadas para quitaros la vida, porque se temen de vuestro ingenio: abrid el ojo y mirad quién llega a hablaros, y no comáis de cosa que os presentaren. (1612, Cervantes: Segunda parte del ingenioso caballero don Quijote de la Mancha)

4. Al Obispo electo de Córdoba, que está en Tarancon, se dice le han venido ya sus bulas, y ahora lo de Pamplona se está controvertiendo aquí entre muchos opositores, por haberse cerrado de campiña el Presidente de Hacienda en que no quiere ordenarse por ningun modo. (1654 - 1658, Barrionuevo, Jerónimo de: Avisos. Tomos I, II, III y IV)

5. [...] entendiese en cuantos males y en cuanto peligro ella estaba metida, esperando por una parte, de hora en hora, el castigo que haría Oroóndates, si fuese avisado por Aquémenes, y temiendo, por otra, no viniese Arsace antes desto a darse la muerte por miedo de no ser toma-

\footnotetext{
5 Cito por la edición de Madroñal y Carbonell (2008).

6 Todos ellos han sido extraídos del CORDE.
} 
da en los amores, determinó de cerrar los ojos a todas las cosas que la amenazaban, y con alguna gran maldad o hacer que se cumpliese lo que Arsace quería, y evitar el presente peligro que esperaba, o quitar de por medio los que podían atestiguar y descubrir todos estos negocios, tramando en su pensamiento de hacellos morir a todos. (1587, Mena, Fernando de: Traducción de la Historia etiópica de los amores de Teágenes y Cariclea de Heliodoro)

6. Pues mi primo muestra gusto en este negocio yo bajo la cabeza; pero antes será bien que se reciba esta causa a prueba y que me informe de algunas personas de su condición y costumbres, y principalmente de aquellas que le trataron al señor Estacio en tiempo de su primera mujer; porque yo tengo más disculpa deste atrevimiento, que tal nombre doy al casarse, y pienso que todos los cuerdos firmarán conmigo. (1620, Salas Barbadillo, Alonso Jerónimo de: El sagaz Estacio, marido examinado)

7. Fuímonos alargando un poco y, donde me pareció lugar conveniente, metí la mano en el seno y saqué el agnusdei de oro, de cuyo precio estaba yo bien informado, como del que lo había pagado. Satisfízole al platero. Crecióle la codicia de comprarlo, porque demás que estaba bien obrado tenía piedras de precio. Pedíle por él docientos escudos, y era muy poco menos lo que había costado de lance. Comenzólo a deshacer, bajándolo de punto: púsole cien faltas y ofrecióme mil reales a la primera palabra. Resolvíme que habían de ser ciento y cincuenta escudos y los valía como un real: no quería bajar de allí; sirva de aviso al que vende, que nunca baje al precio en que ha de dar la cosa, sino espere a que suba el comprador a lo en que la puede llevar. (1599, Alemán, Mateo: Primera parte de Guzmán de Alfarache)

8. Porque querer vivir virtuosamente en un mundo tan malo (donde tantas ocasiones hay para pecar) y estando cercados por una parte de una carne tan mal inclinada, y por otra de tantos demonios y de algunos hombres perversos (que á veces nos hacen más cruda guerra que los demonios) sin ayudarnos de todos estos pertrechos y armas espirituales, es querer subir al cielo sin escalera. Y por falta desto vemos cuán pocos sean los hombres que vivan sin pecados mortales. (1583, Granada, Fray Luis de: Segunda parte de la Introducción del Símbolo de la Fe)

9. Como en semejantes alborotos las dicciones crecen y cada uno canoniza su presunción según se le antoja, murmuraban de don Luis y de la gente de su casa. A él se le subía la mostaza en las narices; mas, como caballero cuerdo, tuvo a mejor disimular con algo y volver a la ciudad su casa y gente. (1599, Alemán, Mateo: Primera parte de Guzmán de Alfarache)

Tras una primera lectura, se percibe que algunas de estas formas se han mantenido idénticas a lo largo de los siglos, mientras que otras han sufrido pequeños cambios y otras, sin embargo, han desaparecido. Entre las primeras, nos encontramos con abrir el ojo, abrir la cabeza, abrir camino, abrir la mano, cerrar los ojos, cerrarse las heridas, bajar la cabeza o bajar el tono. Se trata de expresiones metafóricas que forman parte del caudal léxico que el hablante de español conoce y utiliza habitualmente. ${ }^{7}$

\footnotetext{
7 Transcribo a continuación los significados que Covarrubias recoge para estas expresiones que conservan su identidad formal y de significado: abrir el ojo 'estar muy advertido que no le engañen', abrir la cabeza 'amenaza que se suele hacer, y seguirse de hecho, riñendo', abrir camino 'dar luz y noticia de cómo se haya de guiar algún negocio', abrir la mano 'recibir dones y cohechos', 'cerrar los ojos a la cosa que se va a hacer, acometerla sin considerar mucho si conviene o no', bajar la cabeza 'obedecer', bajar el tono 'hablar no tan recio'. En el caso de cerrarse las heridas solo se recoge el significado literal 'encarnar y hacer cuero' pero no el metafórico.
} 
Por otra parte, hay algunas locuciones que, con el transcurso del tiempo, han ido experimentando pequeños cambios como puede ser la adición u omisión del artículo, la variación en el número o la utilización de expresiones cuasisinónimas: abrir puerta 'dar ocasión, haber concedido o hecho alguna cosa por alguno, que sea ocasión de no poderla negar a otros', cerrar puerta, 'negar, no admitir con determinación'. En estos casos de variación fraseológica las antiguas expresiones siguen siendo fácilmente inteligibles para un hablante actual. ${ }^{8}$ No ocurre lo mismo con otras de las expresiones mencionadas por Covarrubias; así, abrir el cuello, abrir tienda, ${ }^{9}$ abrirse en las razones, cerrarse de campiña, cerrarse las velambres, bajar el halcón de carnes, subir el humo a la chimenea, subirse el humo a las narices, subirsele la mostaza a las narices o subirse en el canto son expresiones opacas ya que aluden a situaciones, acciones, objetos o realidades no existentes hoy o no recordadas, por lo que han perdido su vigencia y su posibilidad, por tanto, de funcionar como metáforas reconocibles. En las siguientes líneas, muestro el significado que les atribuye Covarrubias:

Abrir tienda: salir en público con su trato; suélese tomar en mala parte, hablando de las mujeres libres.

Abrir el cuello: componerle como hoy día se hace, de que hay gente que lo tiene por oficio, y no se corre mal.

Abrirse en las razones: declararse.

Cerrarse de campiña: es determinarse un hombre a no conocer lo que le piden o demandan, sino negarlo.

Cerrarse las velambres: entrar los días en los cuales no se celebran bodas por la Iglesias.

Bajar el halcón de carnes: entre cazadores es enflaquecerle.

Bajar de punto: descaecer del mayor estado.

Subir el humo a la chimenea: Las chimeneas tienen un cañón por donde sale el humo y, por alusión, decimos que se subió el humo a la chimenea, cuando alguno se pone en cólera.

Subirse el humo a las narices: vale enojarse y airarse; es efeto de la cólera y término usado comúnmente, y aun frasis de la Escritura, lib. 2 Regum, cp. 22: «Ascendit fumus de naribus eius» etc. Job, cap. 41: «De naribus eius procedit fumus, sicut ollae succensae atque ferventis». Subirsele la mostaza a las narices: Amostazarse es enojarse, y subírsele la mostaza a las narices lo mesmo. Porque igualmente hacen este efecto el enojo y la mostaza, que alteran la nariz, lugar propio donde se demuestra la saña, y la ira.

Subirse en el canto: salir de tono, para dar más fuerza a la voz de lo necesario.

\footnotetext{
${ }^{8}$ Sigo para el concepto de «variación fraseológica» a Ortega Ojeda/González Aguiar (2005: 92) quienes lo definen como «el fenómeno que se produce cuando una UF, a pesar de estar fijada, se materializa con formas distintas sin que dicho cambio conlleve alteraciones en el significado fraseológico».

${ }^{9}$ En español actual existe abrir/cerrar la tienda con un significado totalmente diferente; así, recoge Seco (2004): 'ser el primero en llegar al trabajo (o el último en salir)'.
} 
Hay también algunas locuciones que no han pervivido pero muestran metáforas fácilmente interpretables por el hablante; me refiero a casos como cerrar la cuenta 'concluirse', cerrarse la mollera 'tener ya seso. Dicen que los niños tienen abierta y tierna la comisura de la cabeza hasta cierta edad; y a los que son livianos decimos: Aun no se les ha cerrado la mollera', bajar las calzas 'bajar las calzas al muchacho, azotarle', o subir al cielo sin escalera 'Como querer subir al cielo sin escalera, de los que intentan hacer una cosa sin los medios necesarios y forzosos'.

Por último, quiero señalar cómo, en ocasiones, las expresiones con las que se recuperan los significados de las antiguas locuciones siguen manteniendo viva la idea de proceso y se sigue recurriendo a verbos de movimiento con significado figurado: cerrarse de campiña = cerrarse en banda; subirse la mostaza a las narices = subirse por las paredes, subirse la sangre a la cabeza. En este sentido, se puede afirmar que el proceso para la creación léxica a partir de verbos de movimiento sigue siendo productivo en español. En el próximo apartado me centraré en las expresiones vigentes en la actualidad.

\section{EXPRESIONES CON ESTOS VERBOS EN ESPAÑOL ACTUAL}

El español muestra, como acabo de comentar, cierta continuidad en el uso de estas construcciones. Las que ahora se recogen son locuciones con una alta frecuencia y una amplia esfera de uso, lo que se ratifica por la abundante documentación encontrada y por el hecho de que, aun teniendo en cuenta que existe una importante diversidad en el español de las distintas áreas hispanohablantes, muchas de las expresiones aquí citadas se utilizan tanto en el español europeo como en el de varios países americanos. ${ }^{10}$ Para la selección he tenido en cuenta los datos aportados por Seco/Andrés (2004), y Ramos/Serradilla (2000), así como mi propia experiencia de hablante.

\subsection{Locuciones idiomáticas: corpus y ejemplos}

ABRIR: abrir boca, abrir brecha, abrir(se) calle, abrir de par en par, abrirse de piernas, abrir el alma, abrir el corazón, abrir el melón, abrir fuego, abrir la boca, abrir la caja de los truenos, abrir la cabeza, abrir la espita, abrir la veda, abrir(se) las carnes, abrir la tienda, abrir los ojos, abrir los ojos como platos, abrir los oídos, abrir los labios, abrir el pico, abrir la caja de Pandora, abrir la mano, abrir la puerta, abrir(se) camino, abrir(se) paso, abrir viejas heridas.

CERRAR: cerrar a piedra y lodo, cerrar con siete llaves, cerrar el ojo, cerrar el paso, cerrar la boca, cerrar la espita, cerrar la tienda, cerrar la veda, cerrar (un) ojo, cerrar a cal y canto, cerrar el grifo, cerrar el pico, cerrar filas, cerrar los oídos, cerrar los labios, cerrarse en banda, cerrar los ojos, cerrar(se) las heridas, cerrar la(s) puerta(s).

BAJAR: bajar a los infiernos, bajar a tierra, bajar(se) al pilón, bajar de la burra, bajar(se) de la parra, bajar(se) de su pedestal, bajar el pistón, bajar el telón, bajar la guardia, bajar las orejas, bajarse del carro, bajarse al moro, bajar(se) de las nubes, bajar(se)

10 Véase cómo los ejemplos recogidos en el CREA que cito a continuación frecuentemente han sido extraídos de textos americanos. 
del burro, bajar la cabeza, bajar la cerviz, bajarse en marcha, bajarse la sangre a los talones, bajar el tono, bajar el listón, bajar los ojos, bajar los humos, bajarse los pantalones.

SUBIR: subir a los altares, subir al trono, subir de punto, subir(se) el pavo, subir el telón, subir el tono, subir en flecha, subirse a la cabeza, subirse a las barbas, subirse el corazón a la boca, subirse el corazón a la garganta, subirse la sangre a la cabeza, subirse a la parra, subir como la espuma, subirse al carro, subir de tono, subirse los humos (a la cabeza), subirse por las paredes.

Antes de proceder a su análisis, propongo algunas muestras de uso de estas expresiones extraídas del CREA, que nos permiten observar su vitalidad en el español actual. ${ }^{11}$

10. Aunque no de forma tan radical, la Escuela Superior de Ingeniería Informática también 'abrirá la mano' en la titulación de segundo ciclo de Ingeniero en Informática, ya que incrementará en 30 las 70 plazas ofrecidas este curso. (El Norte de Castilla, 28/03/2001)

11. De acuerdo con la legislación actual, el cuadro no puede ser exportado y es ilegal cualquier intento subrepticio de venta, cuyo destino sea fuera de España. El hecho de que, en la actual negociación de la posible venta, se baraje como condición la permanencia del cuadro en España durante seis meses al año, no deja de ser una trampa. Significa abrir la puerta para facilitar la salida definitiva del cuadro. No resulta difícil suponer que, tarde o temprano, los nuevos propietarios se negarían a reiterados traslados aduciendo motivos de seguridad. (ABC Cultural, 12/04/1996)

12. Este primer paso le incentivó a buscar en torno a la misma especialidad, la búsqueda de ingresos que complementaran los siempre escasos que reportaba la enseñanza, y así Manuel Usano empezó a encontrar profesionalmente un espacio en que podía reencauzar su vida y aportar al país su experiencia y buen hacer. Igualmente el trabajo que iba realizando le fue abriendo camino, puesto que iban siendo conocidas dentro de la especialidad la cualificación y la experiencia que en este campo Usano podía suponer para el impulso y desarrollo que en Colombia estaba precisando el área. (Revista Internacional de Medicina y Ciencias de la Actividad Física y del Deporte, nº9, marzo 2003) 13. Es un clero que tampoco se interroga sobre la canonización de gentes asesinadas durante la Guerra Civil, tema que la propia jerarquía llevó en años pasados con mucha prudencia por ser consciente de que podía abrir viejas heridas. «En tiempos del pontificado del Papa Pablo VI fue el cardenal Albareda el que le recomendó que no abriese viejas heridas. Ahora esa prudencia se ha acabado.» (La Vanguardia, 02/06/1995)

14. No es mal momento para recordar el poema que escribí cuando Stalin murió. No voy a hacer lo mismo que los demás, que casi todos los demás dirigentes comunistas formados en la época de Stalin. No voy a cerrar a cal y canto mi memoria. Escribí este poema en el mes de marzo de 1953, a las pocas horas de anunciarse oficialmente la muerte de

11 Por razones de espacio, no presento ejemplos de todas ellas. El investigador interesado puede acudir al CREA, ya que en este corpus aparece una amplísima muestra de las locuciones que estoy analizando. 
Stalin. No lo escribí por encargo, fue algo que salió espontáneamente de lo más profundo de mi conciencia enajenada. (1977, Semprún, Jorge: Autobiografía de Federico Sánchez) 15. Pero si estas cantidades eran invertidas en Nicaragua en programas prioritarios de desarrollo, el crédito se podía extender a veinte años y el interés rebajarse a un 2 por 100. Es decir, un regalo. Pues ni siquiera así ha pagado Nicaragua a su espléndido proveedor de crudo; de suerte que, al alcanzar la deuda a 500 millones de dólares, México -que no está en condiciones de tener tales morosos entre sus amigos- se ha visto precisado a cerrar el grifo. Venezuela hace aún más tiempo que dejó de exportar su crudo a Managua, y por las mismas razones. ( $A B C, 07 / 05 / 1985)$

16. Faraiso: Pudiste haberle dicho que estabas sola en el asunto de las drogas. ¿Para qué tuviste que mencionarme a mí? ¡No pudiste cerrar el pico! Raquel: No se me ocurrió que hubiera algo de malo en eso. Faraiso: ¡Mentira! Lo hiciste deliberadamente porque querías que compartiera los riesgos. Negálo si podés. (1982, Shand, William: El sastre, Argentina) 17. ¿Y usted qué piensa, realmente, don Félix Arcadio, o es que a usted le gusta cerrarse en banda cuando se le pregunta sobre lo que de verdad está pasando?... -La voz de Matamoros le sacó de sus cortas elucubraciones... (1996, Chase Brenes, Alfonso: El pavo real y la mariposa, Costa Rica)

18. En el fondo, lo que subyace es la voluntad de no tomar ninguna medida que ahonde aún más las diferencias que mantiene el sindicato con el partido y el Gobierno. Manuel Chaves afirmó ayer que el PSOE tenía la intención de hacer lo posible por cerrar las heridas, una vez que se diera por finalizado el debate de las pensiones, y en consecuencia trataría de no provocar nuevas diferencias. (El País, 01/06/1985)

19. Decir sí al euro no implica cerrar la puerta a los nuevos aires, ni cerrar la discusión a lo que necesita esta nueva Europa. Todo lo contrario. Especialmente cuando esos aires traen nuevas prioridades. Los socialistas han puesto en Malmoe el énfasis en el empleo, la modernización económica y la educación. (El País, 08/06/1997)

20. [...] el mutismo reina en las salas de juego donde supuestamente eran reclutados los niños. «¿Aquí? Imposible». El encargado de uno de ellos, «Las Vegas de Madrid», niega ofendido "que en nuestro local haya pasado nada de eso». Ninguno de los chavales consultados dijo haber sido tentado con las 60.000 pesetas que solían ofrecer los delincuentes. «Yo nunca habría ido. Ni ofreciéndome millones», dice Javier, de 15 años. Mañana hará su viaje de todos los días... al colegio. [...] Los jóvenes, con problemas afectivos y de integración social, caían fácilmente en manos de unos delincuentes que les ofrecían hasta sesenta mil pesetas por «bajarse al moro». (El Mundo, 15/10/1995)

21. «¿Sabe qué? Creo que he fallado por confiado, creí que estaba sobrado en esto. Yo vengo de ser el mejor arquero en el país en esta categoría. En los Campeonatos Nacionales y en los Juegos Nacionales, ganamos y casi no me hicieron goles. Yo veía que a los otros arqueros les hacían goles bobos y que a mí no me pasaba eso y me creí sobrado. Pero acá, que el nivel es más duro, esto me ha servido para bajarme de la nube...», reflexiona con una voz muy baja de volumen. El, que estaba seguro que era el mejor portero, aquí en Chile se ha dado cuenta que aún le falta mucho: (El Tiempo, 21/01/1997, Colombia)

22. [...] el sindicato de jugadores (ABP) se negaba a desconvocar la huelga si los clubes no aceptaban una reducción del número de extranjeros a partir de la próxima temporada. La 
$\mathrm{ACB}$, que tenía un documento suscrito totalmente legal por el cual hasta junio del 2000 los equipos podrían tener tres extranjeros por plantilla, ya había anunciado el lunes su disposición a ceder, pero sólo un año. Es decir, que el límite de foráneos pasara a dos a partir de la campaña 1999-2000. Desde la posición en la que empezaron las conversaciones de ayer, pues, los que tuvieron que bajarse del burro fueron los jugadores. Martín Marín rechazó esta lectura -«no ha habido ni vencedores ni vencidos», dijo. (El País, 28/01/1998)

23. Ayer Buacaram, luego de calificar de 'señorito' al alcalde de Quito, Jamil Mahuad, pidió bajar el tono de las declaraciones entre el Gobierno y la oposición. (El Universal, 08/01/1997, Venezuela)

24. P. Lleva tiempo reclamando una televisión de mayor calidad, ¿qué ha ocurrido en los últimos años? R. Pues que los promotores quieren los máximos resultados, con la mínima inversión y en el menor tiempo posible, y eso hace bajar el listón: la televisión ha degenerado en una especie de fábrica de hacer churros; (El Mundo. Magazine, 16/03/2003)

25. Pero 1994, aunque aciago para algunos importantes, no ha sido tan malo para el vecindario. Ha puesto en crisis la concepción admitida hasta ahora de que el «pelotazo» financiero era en la economía el equivalente de los goles en fútbol. Ha puesto en crisis la convicción de que el enriquecimiento rápido y a costa de otros era un puro asunto privado. Ha permitido ver bajar los ojos a los políticos cuando comentan preocupados que la financiación de los partidos es un problema. (La Vanguardia, 02/01/1995)

26. El tono despótico de la dama me llenó de furor. Tuve ganas de bajarle los humos, pero me contuve porque el encuentro con Ichazo me parecía esencial para el éxito de mi película. En menos de una hora mis ayudantes llegaron con un kilo de marihuana de la mejor calidad, envuelta en hojas de periódico. La chilena se calmó. (2001, Jodorowsky, Alejandro: La danza de la realidad. Chamanismo y psicochamanismo, Chile) 27. La doble victoria, moral y legal, ha dado alas al frente antitabaco, que sueña con acorralar definitivamente a los dos gigantes: Philip Morris y Reynolds. Las dos compañías, acosadas por la Food and Drug Administration [...], tienen abiertos varios frentes legales de costa a costa. Philip Morris, sin embargo, dejó bien claro ayer que no piensa bajarse los pantalones. «Seguiremos luchando hasta el final», declaró un portavoz de la compañía. (El Mundo, 15/03/1996)

28. Antiguamente, cuando los pobres eran realmente pobres, el mando a distancia se llamaba servicio; nada de señales infrarrojas para abrir las puertas del coche: el chófer solucionaba el problema por cuatro perras y además, por el mismo precio, arreglaba los pinchazos. O la criada, sin ir más lejos: le pegabas un grito y te traía el desayuno a la cama y si se empreñaba la despedías por guarra y asunto arreglado. Pero desgraciadamente los tiempos han cambiado, hoy el servicio se ha subido a la parra y hasta la alta burguesía tiene que recurrir al mando a distancia y al portero automático. Sólo los multimillonarios se pueden permitir el lujo de mantener a un equipo de zánganos para que enciendan y apaguen sus televisores o den cuerda al reloj de pulsera. (El Mundo, 15/08/1995: Fernando G. Tola)

29. El ingreso de Figo en la plantilla blanca tuvo efectos desestabilizadores en el Barcelona y, para sorpresa de muchos, los potenciales efectos negativos del fichaje de Figo para las endeudadas arcas del Real Madrid se compensaron, en principio, con la 
proyección mediática mundial que tuvo el fichaje de una de las grandes estrellas del universo futbolístico. La marca madridista subió como la espuma en el mercado mediático mundial; de nuevo el Real Madrid era el astro indiscutible del fútbol a escala planetaria. (2002, Bahamonde Magro, Ángel: El Real Madrid en la historia de España) 30. Yo respetaba las opiniones, pero me jodía, me jodía mucho pensar que esos mismos que criticaban iban a ser después los primeros en subirse al carro de la victoria. (2000, Maradona, Diego Armando: Yo soy el Diego, Argentina)

31. Luego, en la etapa de información, ésta se difundió por todos los medios de comunicación de masas. En ella se informa cómo se transmite y cómo no se transmite el SIDA. La oposición a la información subió de tono y se llevó al plano inconveniente de creencias religiosas y a una supuesta defensa o ataque a la familia. (1994, Castillo Y., Pedro: Aspectos éticos del SIDA, Chile)

32. Pero Ida Ferenczy sabe también cuán altanera se ha mostrado, y se muestra, Fanny Angerer con esas remilgadas aristócratas. Porque la peluquera, y eso es algo que la buena y tolerante Ida Ferenczy no puede negar, es de armas tomar. Y, eso tampoco puede negarlo la condescendiente dama y amiga íntima de la emperatriz, a Fanny Angerer, consciente de ser imprescindible, se le subieron los humos a la cabeza hace ya mucho tiempo. A Ida Ferenczy no le molestan los aires de grandeza adoptados, paulatina pero cada vez más ostentosamente, por la peluquera a medida que su fama ha ido creciendo. (1994, Moix, Ana María: Vals negro) 33. Lady Di llamó el lunes a un funcionario del palacio de Buckingham, en vez de a la reina en persona, para anunciar, de pasada y como si tal cosa, que por cierto había concedido una entrevista en exclusiva a la BBC en la que «hablaba de todo» [...]. El príncipe, según fuentes oficiales, «se subió por las paredes» al recibir la noticia. (La Vanguardia, 16/11/1995)

Destinaré el siguiente apartado a realizar algunos comentarios acerca de estas estructuras.

\subsection{Existencia de metáforas universales y productividad de los verbos de movimien- to para crear locuciones}

Comenzaba este artículo señalando que las expresiones aquí analizadas pueden presentar un significado literal y un significado figurado, posibilidad doble que las diferencia de las llamadas colocaciones. ${ }^{12} \mathrm{E}$ significado figurado viene condicionado por el uso de metáforas reconocidas como tales por la comunidad hispanohablante. Podríamos, incluso, ir más allá y referirnos a las metáforas que aparecen en estas construcciones como metáforas universales. En el mismo sentido argumenta Forment (2002: 35):

12 Véanse para las diferencias entre colocaciones y frases hechas o locuciones Bosque (2001), Koike (2001), Ruiz Gurillo (2002) o Serradilla (2004). Muy interesantes resultan también algunos de los trabajos incluidos en Luque Durán/Pames Bertrán (2005). 
Desde la perspectiva de la lingüística cognitiva, la metáfora se concibe como un proceso mental específico que permite entender unos aspectos de la experiencia, generalmente abstractos e intangibles, en términos de otros, que suelen ser más familiares y concretos. De hecho, la idea fundamental, según la opinión de autores como Georges Lakoff y Mark Johnson, es que los mecanismos que rigen los procesos metafóricos no residen en el propio lenguaje, sino que hay que buscarlos en nuestro sistema conceptual, el cual, a su vez, está profundamente impregnado por los rasgos característicos de nuestra cultura. Así, no es el lenguaje, ya sea poético o coloquial, lo metafórico, sino la propia mente humana, ya que suele estructurar a partir de metáforas el mundo que la circunda.

Y estas metáforas tienen, por tanto, un alcance muy significativo en comunidades diversas. Galán (1993: 154) ya señalaba cómo los verbos de movimiento son especialmente productivos para expresar tiempo, sentimientos, ideas, emociones... en las diferentes lenguas y, aunque hay diferencias entre una lengua y otra porque «la expresión del movimiento metafórico se construye sobre esquemas sintácticos similares a los utilizados para designar el desplazamiento real» y estos esquemas pueden variar, sí parece claro que «el tránsito del ámbito espacial concreto al ámbito abstracto se realiza mediante esquemas conceptuales compartidos por lenguas no necesariamente emparentadas cultural o históricamente».

Efectivamente, los verbos seleccionados para este estudio son verbos de movimiento capaces de entrar en locuciones que no implican un movimiento real, sino un desplazamiento figurado, no solo en español sino también en otras lenguas como luego veremos. Así, en nuestra cultura occidental tenemos diversas metáforas orientacionales y el concepto «abajo» tiene un matiz negativo, frente a lo que está arriba, que es positivo (Lakoff/Johnson 2001; García Jurado 2000; Llamas Saiz 2005), ${ }^{13}$ concepto que se ve ratificado, por ejemplo, por el uso de locuciones en las que participa el verbo caer: caer chuzos de punta, caer en desgracia, caer en la red, caer en saco roto... (Serradilla 2004), o por el hecho de que, aunque pueda considerarse anecdótico, la sociedad se jerarquice a partir de «clases altas» y «clases bajas» y sea posible «subir» o «bajar» en la escala social o en el ámbito laboral.

En el caso de subir/bajar, esta metáfora orientacional también funciona, aunque esto no quiere decir que en todas las situaciones lo que sube es positivo y lo que baja es negativo: basta con pensar en los precios; salvo algún caso excepcional, es claramente preferible para la mayoría de la sociedad que los precios bajen a que suban. Sí observamos, sin embargo, un valor negativo en el caso de bajar a los infiernos, bajar a tierra, bajar de la burra, bajar(se) de la parra, bajar(se) de su pedestal, bajar la guardia, bajar las orejas, bajarse del carro, bajar(se) de las nubes, bajar(se) del burro, bajar la cabe-

13 En el mismo sentido argumenta Forment (2000: 371): «En nuestra cultura suele relacionarse con facilidad la noción «arriba» con la felicidad, la bondad, la alegría y las virtudes, y la noción «abajo» con la tristeza, la maldad y la humillación». 
za, bajar la cerviz, bajarse en marcha, bajarse la sangre a los talones, bajar el listón, bajar los ojos, bajar los humos, bajarse los pantalones. Asimismo, se percibe un matiz positivo en subir a los altares, subir al trono, subir de punto o subir como la espuma. No obstante, es difícil afirmar que este sea el valor generalizado de las expresiones con subir ya que se perciben como negativas locuciones como las siguientes: subir(se) el pavo, subirse a la cabeza, subirse a las barbas, subirse el corazón a la boca, subirse la sangre a la cabeza, subirse a la parra, subirse los humos a la cabeza, subirse por las paredes. En este sentido, parece que la metáfora «abajo = negativo» está más generalizada que «arriba $=$ positivo».

Por otra parte, abrir es también positivo, frente a cerrar, que es negativo; véase en este sentido la diferencia entre «una persona abierta» y «una persona cerrada», o entre una «sociedad abierta» y otra más cerrada. También en las expresiones se percibe un matiz positivo en abrir la puerta, abrir los ojos, abrir el corazón o abrir la mano frente a cerrar la puerta, cerrar los ojos, cerrarse en banda o cerrar el grifo. No obstante, este sentido metafórico de ambos verbos no se observa de forma tan generalizada como en el caso de las locuciones que indican movimiento en una dirección determinada. En el caso de abrir/cerrar hablamos de metáforas ontológicas basadas en la experiencia física con los objetos que nos rodean. Dice Forment (2000: 364):

Los verbos que aparecen en estas primeras expresiones - entrar, caber, meter, pasar, venir, llevar, sacar, etc. $-{ }^{14}$ son verbos que empleamos habitualmente en la expresión de acciones cotidianas en relación con objetos simples. A partir de esa experiencia previa, tangible, física de cualquier persona con un recipiente, el lenguaje conforma las unidades mencionadas $[\ldots]$.

Además, hay que tener en cuenta, tal y como señalaba Nissen (2006: 105), cómo la metáfora «saber es ver» es de carácter general y, si tenemos en cuenta que saber es algo positivo, entenderemos mejor que una expresión como abrir los ojos tenga un carácter positivo frente a cerrar los ojos que significa no ver y, por lo tanto, no saber.

Una vez considerada la posibilidad de estas locuciones para expresar significados figurados, volveré por un momento a la realidad del español clásico: es necesario reseñar cómo el diccionario de Covarrubias recoge pocas expresiones con los verbos analizados si lo comparamos con el número de expresiones que aparecen, por ejemplo, con otros verbos como andar, caer, echar, ir, llevar, meter, venir o volver (Serradilla 2006); no obstante, con el transcurso del tiempo estos verbos empiezan a ser más productivos en el sentido de que empiezan a aparecer cada vez con más frecuencia en locuciones idiomáticas; no llegan al punto de hacer (Sánchez Jiménez 2009) o dar (Radulescu 2006, 2009) pero sí tienen una presencia realmente significativa en nuestra lengua.

En este sentido, es de destacar que los verbos amplios, verbos más extensos, más infraespecificados, participan con más facilidad en expresiones metafóricas como

14 Añadiríamos abrir y cerrar. 
las analizadas que aquellos que tienen una mayor especificidad semántica, es decir, un significado más específico, más concreto. Así, no encontraremos frases hechas con retornar o deslizar, o con otros verbos cultos como vilipendiar o tergiversar ya que no todos los verbos tienen la misma capacidad para trasponerse metafóricamente.

Por otra parte, también es fácil detectar que los verbos que participan en frases hechas suelen ser verbos que presentan una alta frecuencia de uso en la lengua. Así, ir, andar, caer, subir, bajar, abrir, cerrar, entre los verbos de movimiento, o ser y estar, entre los de estado, son verbos que entran habitualmente en locuciones.

Es necesario, sin embargo, tener en cuenta que la frecuencia de uso de las distintas expresiones en las que participan estos verbos dista mucho de ser similar; así, como señala Nissen (2006: 106), el hecho de que «abrir» se identifique con «saber» hace que las expresiones abrir/cerrar los ojos sean muy frecuentes en las distintas lenguas:

[...] se puede abrir y cerrar los ojos y, por lo tanto, el abrir o el cerrar los ojos hace posible

o bloquea la posibilidad de saber. Es fácil encontrar ejemplos que demuestran este uso:

(34) a. A menudo he intentado abrirle los ojos.

b, I often tried to open his eyes.

(35) a. El juez cerró los ojos a la evidencia.

b. The judge closed his eyes for the evidence.

Además en casos como este o en el caso de abrir/cerrar la boca estamos jugando con la capacidad de las partes del cuerpo para ser usadas de forma metafórica o, incluso, metonímica. Recojo de nuevo unas palabras de Forment (2000: 368-9) que aluden a la motivación por la que las partes del cuerpo entran con tanta frecuencia en estas expresiones:

Entre los constituyentes de algunas de esas expresiones figura de nuevo la mención de una parte del cuerpo humano porque la relación entre nuestro cuerpo y el entorno que nos rodea es un punto de referencia fundamental de nuestro sistema conceptual y de orientación.

Hablamos de metáforas orientacionales y, en este sentido, es lógico que se recurra a estas palabras. Téngase en cuenta también que, como ya señalaron Lakoff y Johnson, los ojos se entienden como recipientes ${ }^{15}$ y la boca además de un objeto es la palabra por lo que la apertura se identifica con «hablar» y el cierre con «callar». ${ }^{16}$

15 No se trata, sin embargo, de un recipiente inerte, ya que los ojos funcionan como dispositivos que permiten poner en marcha, activar una reacción, como, por ejemplo «llegar a saber»; al fin y al cabo, las cosas entran por los ojos, pero no se alojan en ellos.

16 Véase también García-Page (2008) quien estudia en profundidad el uso de partes del cuerpo en las locuciones idiomáticas. 
Por el contrario, otras locuciones como abrir la caja de los truenos, cerrar a piedra y lodo, bajarse al moro o subir(se) el pavo son mucho menos usadas, debido, probablemente, a que presentan metáforas menos transparentes.

Hay otro punto en el que también considero interesante insistir porque es significativo para entender la productividad de estas expresiones: muchas frases hechas presentan casos de antonimia (García Page 2008: 410). Véanse las siguientes oposiciones:

abrir los ojos - cerrar los ojos; abrir la espita - cerrar la espita; abrir la veda - cerrar la veda; abrir el pico - cerrar el pico; abrir los oídos - cerrar los oídos, abrir los labios - cerrar los labios, abrir viejas heridas - cerrar(se) las heridas; abrir la puerta - cerrar la(s) puerta(s); abrir(se) paso - cerrar el paso.

bajar(se) de la parra - subirse a la parra; bajarse del carro - subirse al carro; bajar el telón subir el telón, bajar el tono - subir el tono; bajar los humos - subirse los humos (a la cabeza).

Es evidente que ambos pares de verbos pueden participar en locuciones antónimas pero la productividad no es la misma ya que, mientras que abrir/cerrar suelen presentar frecuentemente relaciones de antonimia, en el caso de bajar/subir parecen existir más limitaciones. Esto tiene que ver con la propia realidad en el sentido de que los objetos «que se abren» normalmente se pueden cerrar (estamos hablando de un significado literal) pero no todos los objetos que bajan han de volver a subir. ${ }^{17}$ Esta misma situación se observa cuando el movimiento no es real sino que se trata de un desplazamiento figurado.

No podemos olvidar, finalmente, cómo en el caso de los verbos analizados el $D R A E$ muestra un número importante de acepciones: para bajar se recogen 11, y hasta 15 acepciones presenta el verbo subir. Mayor es el número de estas con los dos verbos restantes; así, la entrada abrir incluye 34 acepciones y el $D R A E$ llega a recoger hasta 36 acepciones de cerrar, lo que da cuenta de las posibilidades combinatorias de dichos verbos, la amplitud de su significado y, por tanto, su disponibilidad para poder entrar en locuciones idiomáticas.

\subsection{Estudio comparativo con otras lenguas}

Son cada vez más frecuentes en la bibliografía actual los estudios comparativos sobre fraseología. Trabajos como los de Brumme (2009), Forment (2000), Galán (1993), García Jurado (2000), Nissen (2006), Radulescu (2005, 2006, 2009) o Serradilla Castaño $(2001,2004)$ no son más que una muestra del interés que la fraseología comparada está despertando entre los estudiosos de la lengua.

Como señalaba en un artículo anterior (Serradilla 2004: 140),

17 Aunque en español hay un dicho: «todo lo que sube baja», es evidente que no todo lo que baja vuelve a subir. 


\begin{abstract}
Existen determinadas metáforas universales; así las orientacionales son relativamente similares en las distintas lenguas. Por otra parte, no podemos perder de vista que hay diferencia entre las distintas lenguas y que las lenguas analizadas se valen de distintos recursos para representar la realidad, por ello, mientras el español se vale con gran facilidad de verbos absolutos o genéricos para expresar el movimiento figurado, otras lenguas como el inglés o el alemán son más reacias a este uso y optan por verbos más concretos para expresar estas metáforas. En todo caso, y aunque no hay coincidencia en todas las locuciones analizadas, se hace evidente que tanto el inglés como el español tienen la posibilidad de recurrir a verbos de movimiento para expresar desplazamientos figurados. ${ }^{18}$
\end{abstract}

Así, como se ha comentado más arriba, en muchas de las lenguas occidentales se recoge la idea de que «Lo bueno/lo alegre/lo virtuoso está arriba y lo malo/lo triste/lo no virtuoso está abajo» (Forment 2000: 375). Esto lo hemos podido ver en el caso del español pero puede ilustrarse también con ejemplos del italiano, lengua cercana a la nuestra, e, incluso y con la misma o mayor frecuencia, en inglés, idioma de origen y evolución muy diferentes:

Italiano ${ }^{19}$ : ascendere all'altare, ascenderé al trono, alzare il sipario, alzare il tono, scendere a terra, scendere dal piedestallo, scendere in corsa, abbassare la guardia, abbassare il tono, abbassare gli occhi.

Inglés ${ }^{20}$ : to lift one's head up high, to raise one's head, not to lift one's head, to ascend to the throne, to come up/turn up trumps, to get-up-and-go, to come/go up in the world, not lift a finger, to cut someone down to size, to come (back) down to earth (with a bang/bump/jolt, to bow one's head in resignation, to come down off one's high horse, to go straight up, to go down in people's eye, to lower the curtain, to drop/lower your guard, to lower your sights, to lower the tone, to come/go down in the world, to go down the wrong way, to go down the plughole, to go down/fall like ninepins British, to go down like a lead balloon, to go downhill, to be/come down on somebody like a ton of bricks. ${ }^{21}$

18 En ocasiones, en inglés se observa, como me señala Santiago U. Sánchez, que hay una mayor tendencia a desdoblar el movimiento y el modo de movimiento: por ejemplo GO + dirección (down). Seguimos hablando, en todo caso, de verbos de movimiento para expresar desplazamientos metafóricos.

19 Agradezco a Valeria Camporesi su esfuerzo para facilitarme todos los ejemplos de las expresiones en italiano.

${ }^{20}$ Las locuciones inglesas presentadas proceden del Cambridge International Dictionary of Idioms [on line], de Carbonell (1995) y de Ramos/Serradilla (2000). Obsérvese que hay un importante predominio de las expresiones que indican 'bajar' frente a las que indican 'subir'; se trata de un predominio mucho más acentuado que en español.

${ }^{21}$ No todas las expresiones que utilizan un verbo con el significado 'bajar' expresan siempre un matiz negativo (por ejemplo: go down that road). Se trata de la misma situación que veíamos para el español. 
No puedo en este breve artículo citar ejemplos de todas las lenguas que recurren a esta metáfora, ${ }^{22}$ pero creo que la muestra presentada nos permite corroborar la hipótesis de que existen metáforas universales y de que en lenguas diferentes existe la misma posibilidad de usar verbos de movimiento por su facilidad para trasponerse como usos figurados de sentimientos y sensaciones, y para indicar, por tanto, con su extensión metafórica, un movimiento que no ha de ser interpretado literalmente.

Lo mismo ocurre en el caso de los verbos abrir/cerrar:

Italiano: aprire la bocca, aprire il fuoco, aprir bocca, aprire la caccia, aprire gli occhi, aprire le orecchie, aprire le labbra, aprire il becco, aprir la mano, aprir la porta, aprire il vaso di Pandora, aprire vecchie ferite. chiudere un occhio, chiudere la bocca, chiudere la cacica, chiudere il sipario, chiudere un occhio, chiudere il becco, serrare le fila, chiudere gli occhi, chiudere la/e porta/e.

Inglés: not to open one's mouth, to shut one's mouth, to shut one's trap, to keep one's mouth shut ${ }^{23}$, to open fire, to open one's mind, to crack one's head open, to open one's eyes wide, to open a can of worms, to open the door to something, to open (new) doors, to open somebody's eyes to something, to open the floodgates, to open your heart, to open/ reopen old wounds, to be (wide) open to abuse/criticism etc., to open a Pandora's box, to open the way for/to something, to close/shut your eyes to something, to close your eyes and think of England, to have all avenues closed, to close ranks, to be closed to the bone, to close/shut the door on something, to close/near at hand, to close/dear to somebody's heart... ${ }^{24}$

Se observa, en fin, que estamos ante un procedimiento recurrente en muchas lenguas, que resulta especialmente rentable para expresar desplazamientos figurados. Los mismos verbos son utilizados por hablantes de español, italiano, inglés, francés o catalán, entre otras lenguas, para formar locuciones que sugieren las mismas imágenes.

\section{REFLEXIONES FINALES}

A lo largo de este trabajo ha quedado demostrada, a la vista de los ejemplos tanto del español clásico como del español actual, la productividad de los verbos estudiados para entrar a formar parte de locuciones idiomáticas en español; productividad que se va viendo acrecentada con el paso de los siglos.

El motivo por el que abrir, cerrar, bajar y subir, al igual que otros verbos de movimiento, forman parte de estas locuciones con tanta frecuencia hay que buscarlo en su capacidad para extenderse metafóricamente de manera que pasan de designar un movimiento real a designar un movimiento figurado. Esta capacidad de transposición

22 Valgan como ilustración algunos otros ejemplos del catalán y el francés: catalán: alçar el cap; abaixar el cap/acotar el cap; francés: lever la tête; baisser o courber la tête.

23 En los ejemplos anteriores hay que tener en cuenta que también funciona la metáfora ontológica «la boca es un objeto abierto o la boca es un canal» (Forment 2000: 375).

24 Véase también la siguiente muestra de otras lenguas: catalán: no obrir la boca/no obrir els llavis, cloure la boca; tancar la boca; obrir la boca; francés: ne pas ouvrir la bouche. 
la encontramos en todas las lenguas analizadas puesto que existen metáforas universales reconocidas como tales por los hablantes: bajar y cerrar nos transmiten una idea negativa mientras que abrir y subir traen consigo una imagen positiva.

No quiere esto decir que todas las lenguas utilicen siempre los mismos verbos para expresar las mismas realidades -téngase en cuenta que en la creación de locuciones idiomáticas intervienen también otros factores históricos y culturales, y son pocos los casos en los que se puede hablar de equivalencia plena entre las diversas lenguas - pero sí que hay importantes similitudes debido a que existe un mismo mecanismo disponible en todas ellas y se recurre a él con relativa frecuencia.

Así, la metáfora, y también la metonimia, dejan de ser consideradas únicamente como figuras retóricas y empiezan a ser analizadas en la moderna lingüística como mecanismos fundamentales de la creación léxica. Estamos, en fin, ante un hecho sobre el que los lingüistas debemos reflexionar ya que es de enorme trascendencia tanto en el campo de la traducción como en el ámbito de la enseñanza de segundas lenguas. ${ }^{25}$

\section{Bibliografía}

BosQue, Ignacio (2001) «Sobre el concepto de colocación y sus límites.» LEA 23/1, 9-40.

BosQue, Ignacio (2004) (dir.) REDES. Diccionario combinatorio del español contemporáneo. Madrid: SM.

BRUMME, Jenny (2009) «Las unidades fraseológicas con numeral en los diccionarios generales.» En: E. De Miguel et al. (dir.), 501-530.

Cambridge International Dictionary of Idioms $\langle$ http: //dictionary. cambridge. org/ Default.asp?dict=I > (fecha de consulta 16 de junio de 2009).

CARBONell BASSET, Delfín (1995) Diccionario fraseológico inglés-castellano, castellano-inglés, Barcelona: Ediciones del Serbal.

Cejador Y Frauca, Julio (2008) Diccionario fraseológico del siglo de Oro (Fraseología o estilística castellana). Edición a cargo de Abraham Madroñal y Delfín Carbonell. Barcelona: Ediciones del Serbal.

Corpas PASTOR, Gloria (1997) Manual de fraseología española. Madrid: Gredos.

CORPAS PASTOR, Gloria (2003a) Diez años de investigación en fraseología: análisis sintácticosemánticos, contrastivos y dialectológicos. Madrid: Iberoamericana - Vervuert.

CORPAS PASTOR, Gloria (dir.) (2003b) Las lenguas de Europa: estudios de fraseología, fraseografía y traducción. Granada: Comares.

CovarRubias, Sebastián de (1995 [1611]) Tesoro de la lengua castellana o española. Ed. de Felipe C.R. Maldonado, revisada por Manuel Camarero. Madrid: Castalia.

De Miguel, Elena/Azucena Palacios/Ana Serradilla (dir.) (2006) Estructuras léxicas y estructuras del léxico. Frankfurt: Peter Lang.

25 La enseñanza de la fraseología en la clase de ELE cada vez va despertando más interés y la bibliografía sobre el tema está creciendo considerablemente. En estas pocas páginas ha de quedar forzosamente excluido un asunto de tan amplio alcance. Véanse, entre otros muchos, Penadés (2002) o Serradilla (2001). 
De Miguel, Elena/Santiago U. SÁnchez Jiménez/Ana Serradilla/Romana Radulescu/Olga Batiukova (dir.) (2009) Fronteras de un diccionario: las palabras en movimiento. San Millán de la Cogolla: Cilengua.

Forment, Mar (2000) «'Universales metafóricos' en la significación de algunas unidades fraseológicas.» Revista de Lingüística Española 30/2, 357-381.

GALÁN RodrígueZ, Carmen (1993) «Aproximación al estudio de los verbos de movimiento en alemán y en español: movimiento real y empleos figurados.» Anuario de Estudios Filológicos XVI, 147-158.

GARCía JuRADO, Francisco (2000) «Las 'metáforas de la vida cotidiana' ('metaphors we live by') en latín y su proyección etimológica en castellano.» En: M. Martínez et al. (dir.), Cien años de investigación semántica: de Michel Bréal a la actualidad. Actas del Congreso Internacional de Semántica. (Universidad de La Laguna 27-31 de octubre de 1997). II. Madrid: Ediciones Clásicas, 1571-1584.

García Page, Mario (2008) Introducción a la fraseología española. Barcelona: Anthropos.

Gómez Molina, José Ramón (2004) «Las unidades léxicas del español.» En: J. Sánchez Lobato/I. Santos Gargallo (dir.), La enseñanza del léxico en español como segunda lengua/lengua extranjera. Madrid: SGEL, 27-50.

KoIKe, Kazumi (2001) Colocaciones léxicas en el español actual: estudio formal y léxico-semántico. Madrid: Universidad de Alcalá/Takushoku University.

LAKoff, George/Mark Johnson ( $\left.{ }^{5} 2001\right)$ Metáforas de la vida cotidiana. Madrid: Cátedra.

Lewis, Michael (1993) The Lexical Approach. Londres: Language Teaching Publications.

Llamas Saíz, Carmen (2005) Metáfora y creación léxica. Pamplona: Ediciones de la Universidad de Navarra.

Luque Durán, Juan/Antonio PAmes Bertrán (dir.) (2005) La creatividad en el lenguaje: colocaciones idiomáticas y fraseológicas. Granada: Universidad de Granada.

NisSEN, Uwe Kjaer (2006) « ‘Ojo!' Un análisis contrastivo de metáforas y metonimias relativas al 'ojo' en español y en inglés.» En: E. De Miguel et al. (dir.), 95-110.

Ortega Ojeda, Gonzalo/Ma I. González Aguiar (2005) «En torno a la variación de las unidades fraseológicas.» En: R. Almela/E. Ramón Trives/G. Wotjak (dir.), Fraseología contrastiva (con ejemplos tomados del alemán, español, francés e italiano). Murcia: Universidad de Murcia/Universität Leipzig, 91-109.

PenAdÉs, Inmaculada (2002) Diccionario de locuciones verbales para la enseñanza del español. Madrid: Arco/Libros.

RADULESCU, Romana (2005) «Construcciones idiomáticas con el verbo salir en español, inglés y rumano.» Verba Hispánica XIII, 99-111.

RADUlESCU, Romana (2006) «Estudio contrastivo de expresiones idiomáticas en español, inglés y rumano.» En: E. De Miguel et al. (dir.), 111-128.

RADUlESCU, Romana (2009) «Sobre cuánto puede dar de sí el verbo dar en fraseologismos españoles y rumanos.» En: E. De Miguel et al. (dir.), 469-500.

Ramos, Alicia/Ana Serradilla (2000) Diccionario Akal del español coloquial. 1492 expresiones del español actual y más... Madrid: Akal.

Real Academia Española: Banco de datos (CORDE) [en línea]. Corpus diacrónico del español. <http://www.rae.es> (fecha de la consulta: mayo-junio de 2009). 
Real Academia Española: Banco de datos (CREA) [en línea]. Corpus de referencia del español actual. <http://www.rae.es〉 (fecha de la consulta: mayo-junio de 2009).

Real Academia Española (222001) Diccionario de la lengua española. Madrid: Espasa-Calpe.

Ruiz Gurillo, Leonor (1998) La fraseología del español coloquial. Barcelona: Ariel.

Ruiz Gurillo, Leonor (2002) «Compuestos, colocaciones, locuciones: intento de delimitación.» En: A. Veiga Rodríguez et al. (dir.), Léxico y gramática. Lugo: Tris Tram, 327-339.

SÁnchez Jiménez, Santiago U. (2009) «Hacer: un verbo que sirve para casi todo.» En: E. De Miguel et al. (dir.), 195-232.

SECo, Manuel/Olimpia ANDRÉs (2004) Diccionario fraseológico documentado del español actual. Madrid: Aguilar.

Serradilla Castaño, Ana (2001) «La enseñanza de frases hechas: un método para integrar la cultura en el aula.» En: Ma A. Martín Zorraquino/C. Díez Pelegrín (dir.), ¿Qué español enseñar? Norma y variación lingüísticas en la enseñanza de español a extranjeros. Actas del XI Congreso Internacional de ASELE. I. Zaragoza: Universidad, 657-664.

Serradilla Castaño, Ana (2004) «Ir y caer como constituyentes de locuciones fraseológicas que no implican movimiento.» Verba Hispánica XII, 131-141.

Serradilla Castaño, Ana (2006) «Expresiones idiomáticas con verbos de movimiento en la historia del español: desde el siglo XVII hasta la actualidad.» En: E. De Miguel et al. (dir.), 73-93.

Wotjak, Gerd (1998) Estudios de fraseología y fraseografía del español. Frankfurt: Vervuert.

Zuluaga, Alberto (1992) «Spanisch: Phraseologie.» En: G. Holtus et al. (dir.), Lexicon der Romanistischen Linguistik. VI/1. Tübingen: Max Niemeyer Verlag, 125-131. 


\section{Resumen \\ ABRIR, CERRAR, SUBIR Y BAJAR: LA PRODUCTIVIDAD DE LOS VERBOS DE MOVIMIENTO COMO ELEMENTOS CONSTITUTIVOS DE LOCUCIONES IDIOMÁTI- CAS EN ESPAÑOL}

En este trabajo se estudian los valores metafóricos de las locuciones formadas por abrir, cerrar, bajar y subir: abrir la mano, cerrar el grifo, bajarse los pantalones, subirse a la parra... Se presenta una abundante documentación y se analiza la capacidad de cada uno de los verbos que constituyen estas expresiones para utilizarse de forma figurada. Se llama también la atención sobre el hecho de que los verbos seleccionados participan en estructuras de este tipo desde antiguo y todavía hoy siguen siendo productivos en la creación de frases hechas debido a la existencia de metáforas universales («arriba» es positivo mientras que «abajo» es negativo). Asimismo, se presta atención al significado de cada uno de estos verbos y a sus posibilidades combinatorias; también se centra el interés en la rentabilidad de estos verbos para participar en expresiones figuradas. Se cierra el artículo con un estudio comparativo entre la situación del español y la de otras lenguas y se insiste en la presencia de expresiones figuradas formadas por los mismos verbos, como corresponde a la existencia de metáforas de carácter universal que funcionan en lenguas de tipología diferente.

\section{Povzetek}

\section{ABRIR, CERRAR, SUBIR Y BAJAR: PRODUKTIVNOST GLAGOLOV GIBANJA KOT SESTAVNIH ELEMENTOV IDIOMATIČNIH IZRAZOV V ŠPANSKEM JEZIKU}

Avtorica obravnava metaforične vrednosti stalnih besednih zvez, ki jih tvorijo glagoli abrir, cerrar, subir in bajar (abrir la mano, cerrar el grifo, bajarse los pantalones, subirse a la parra...). S pomočjo mnogovrstnih primerov analizira možnosti rabe omenjenih glagolov v prenesenih pomenih. Posebej izpostavi dejstvo, da se ti glagoli sicer od nekdaj uporabljajo tudi v prenesenem pomenu, vendar še danes velja opozoriti na njihovo produktivnost pri tvorjenju stalnih besednih zvez, predvsem zaradi obstoja univerzalnih metafor (pozitivno naravnan 'zgoraj' in negativno naravnan 'spodaj'). Avtorica se posebej osredotoči na pomen vsakega izmed omenjenih glagolov ter osvetli raznolike možnosti njihovega združevanja, hkrati pa pretrese učinkovitost udeležbe teh glagolov v figurativnih strukturah. Članek zaokroži primerjalna študija o stanju v španščini in drugih jezikih, ki potrjuje splošno prisotnost figurativnih struktur z glagoli gibanja in s tem njihovo univerzalnost. 